Linguagem em (Dis)curso - LemD, v. 8, n. 2, p. 265-287, maio/ago. 2008

\title{
A LEITURA E O PROCESSAMENTO DA ANÁFORA CONCEITUAL
}

Adriana da Silva*

\begin{abstract}
Resumo: Apresentamos uma investigação sobre a leitura de anáfora conceitual (AC). Em um experimento com universitários, investigamos como eles lêem as anáforas. Realizamos um teste self-paced e apresentamos frases contendo anáforas conceituais e outras com anáforas pronominais (AP). Esperávamos que as anáforas conceituais fossem lidas mais lentamente do que as outras anáforas. Os resultados mostraram que não houve diferença significativa na leitura das anáforas. Nossa conclusão é que a leitura é um processo dinâmico e que os leitores têm um papel importante neste processo.
\end{abstract} Palavras-chave: coesão textual; anáfora conceitual; anáfora pronominal; leitura; cognição.

\section{INTRODUÇÃO}

O estudo do processamento e da resolução de anáforas recebe muita atenção dos pesquisadores de diferentes áreas (TYLER; MARSLEN-WILSON, 1982; GERNSBACHER, 1991; OAKHILL et al. 1992; ARNOULD, 1998; MARCUSCHI, 2000a, 2000b, 2000c; LEFFA, 2001; KOCH, 2002; CAVALCANTE; BIASI-RODRIGUES; CIULLA, 2003; APOTHÉLOZ, 2003; HAAG; OTHERO, 2003; SILVA, 2004; CHAMPOLLION, 2006). Como já era de se esperar, existe muita divergência na explicação desse fenômeno, pois as teorias enfocam aspectos diferenciados, como os cognitivos, sociais e discursivos.

Através do estudo do processamento e da resolução anafórica, procura-se compreender mais sobre os mecanismos de coesão e

\footnotetext{
* Professora da Universidade Federal de Viçosa. Doutora em Lingüística. Pós-doutoranda na Universidade Federal de Minas Gerais. E-mail: <adriasilva@terra.com.br>.
} 
coerência, fatores responsáveis pela textualidade do texto. As anáforas podem ser consideradas como pistas textuais que ajudam o leitor a estabelecer a compreensão do texto, pois permitem ao leitor estabelecer relações entre aspectos lingüísticos e extralingüísticos. Estudá-las é importante, para nos levar a entender mais como se dá a compreensão textual. Além disso, ressaltamos que o seu estudo não deve ser feito apenas numa perspectiva estritamente lingüística, pois fatores discursivos e contextuais influenciam no processamento anafórico, ainda mais no caso de anáfora não-correferencial.

A referência, os fenômenos correferenciais e não-correferenciais, assim como o fenômeno da referenciação, passaram a ser discutidos no Brasil a partir da década de 90 . Neste trabalho, simplificamos a noção de correferência, que é mais bem analisada nos trabalhos de Koch e Marcuschi (1998), Koch (1999), Marcuschi (2000a, 2000b, 2000c) e Cavalcante, Biasi-Rodrigues e Ciulla (2003).

Inicialmente, a anáfora foi considerada uma espécie de substituta de um item lexical antecedente que se retomava no texto, mas há casos, como o das anáforas conceituais, nos quais as anáforas não reativam referentes previamente apresentados no texto.

Há casos em que as anáforas, por exemplo, violam uma restrição morfológica, segundo a qual a anáfora e seu antecedente devem apresentar os mesmos traços de gênero e número. Uma anáfora desse tipo é aqui denominada anáfora conceitual (AC), aquela que é representada por um $\mathrm{Pro}^{1}\left[+\mathrm{Pl}^{2}\right]$ que remete a um antecedente textual, um $\mathrm{SN}^{3}$ ou $\mathrm{N}^{4}$ $\left[-\mathrm{Pl}^{5}\right]$.

A violação da regra morfológica pode representar uma dificuldade a mais no complexo processo de leitura e compreensão. Assim, ao detectar o pronome anafórico, o leitor pode ter dificuldade em compreender o uso do pronome, pois ele não está retomando um antecedente, mas remetendo a um antecedente a partir do qual o leitor compreende conceitualmente a anáfora. Conseqüentemente, mais

\footnotetext{
1 Pronome.

2 Plural.

${ }^{3}$ Sintagma Nominal.

4 Nome.

${ }^{5}$ Singular.
}

SILVA - A leitura e o processamento... 
cálculos inferenciais seriam necessários para a compreensão da anáfora conceitual.

Como já afirmamos, a anáfora é um fenômeno lingüístico que permite ao leitor estabelecer uma relação semântica entre itens lexicais de um texto. Dessa forma, ela o ajuda a compreender as relações entre as partes que formam o texto como um todo significativo, possibilitandolhe construir a coerência textual. Exemplo de retomada:

(1) O jornalista acompanhou os times ao estádio. Eles fizeram uma partida importante.

Em (1), por exemplo, a anáfora Eles retoma o antecedente os times e concorda com ele em pessoa e número. Em outras palavras, essa anáfora está se referindo explicitamente ao SN antecedente, de forma que podemos concluir que os times fižram uma partida. Em (1), a anáfora e $\mathrm{o}$ antecedente são correferenciais. Trata-se, portanto, de uma anáfora pronominal (AP). Já em (2) há um exemplo clássico de AC.

(2) O jornalista acompanhou o time ao estádio. Eles fizeram uma partida importante. ${ }^{6}$

Em (2) não podemos dizer que a anáfora Eles retoma diretamente o SN o time, pois não há concordância de número entre a anáfora e o seu antecedente. Nesse caso, a anáfora remete ao antecedente $o$ time, não se referindo a ele propriamente. Tanto é que não podemos substituir Eles por o time na seqüência textual. Na verdade, Eles se refere aos sujeitos, os seres [+ HUMANOS] que compõem o time, ou seja, os jogadores.

Partimos da hipótese de que o leitor é capaz de compreender ambas as seqüências porque, durante a leitura, estabelece relações entre fatores lingüísticos e extralingüísticos. Mas consideramos, a princípio, que o processo de compreensão de (1), por exemplo, poderia ser menos complexo do que o de (2), pois neste o leitor deveria fazer maior elaboração cognitiva para compreendê-lo como um todo significativo. Nesse caso, ele procura estabelecer conexões entre a informação apresentada e aquelas que foram anteriormente apresentadas no texto (CLARK, 1977; SWINNEY; OSTERHOUT, 1990), e isso levaria mais tempo.

${ }^{6}$ Este exemplo também foi usado no experimento. 


\section{8}

Em (1), ao ler Eles, o leitor buscaria relacionar diretamente a anáfora a um antecedente textual (times), auxiliado por traços morfológicos de número e pessoa. Ao ler esse antecedente, ativaria um determinado conceito que seria retomado durante a leitura da anáfora. Como não há, em (2), uma relação direta entre a anáfora Eles e o antecedente time, ele poderia parar na leitura do pronome, podendo, então, inferir que não se trata de um texto coerente. Isso devido à não concordância, na superfície textual, entre o pronome e o antecedente textual. No entanto, ao perceber uma possível relação, poderia retomar o antecedente, mas o remeteria a uma relação conceitual, possibilitando construir um sentido. Podemos, então, estabelecer que a AC poderia exigir um maior processamento, uma vez que não há concordância de gênero e isso poderia dificultar a compreensão.

É importante ressaltar que algumas teorias não aceitam essa hipótese, pois consideram que os leitores são capazes de processar quase que automaticamente casos como esse, produzindo a chamada concordância ideológica. Daí o interesse em se fazer um experimento para medir o tempo de leitura das anáforas e verificar se os leitores realmente demoram mais tempo na leitura das conceituais ou não.

Comparando a AC com a AP, podemos supor que a leitura da AC pode exigir mais processamento cognitivo do que a outra. Na leitura de texto onde ocorresse a AP, o leitor ativaria frames como faz na leitura de qualquer texto, porém só precisaria relacioná-la a um conceito já ativado por um antecedente, pois encontra os mesmos traços morfossintáticos do antecedente. Já na leitura de uma AC, o leitor ativaria frames para cada item lexical; contudo, como não encontra os mesmos traços morfossintáticos nos antecedentes, é obrigado, estrategicamente, a selecionar um conceito ativado por um desses antecedentes e, assim, construir o sentido para o texto. Isso poderia, de certa forma, confundir o leitor.

De acordo com Fillmore (1986), um frame nada mais é do que um modelo semântico para representar a compreensão daquilo que é veiculado em um texto. Os frames podem ser considerados como ferramentas para organizarmos os conceitos ativados durante a leitura, por exemplo, e as relações entre esses conceitos - com base em nossos conhecimentos. 
Assumimos, por hipótese, que as anáforas conceituais têm um custo de processamento maior do que as anáforas pronominais, pois demandariam maior carga de conhecimento e, por isso, seriam lidas mais lentamente. Para explicarmos esse fenômeno, recorreremos aos frames ativados durante a leitura de textos com AC e AP, para estabelecer a diferença entre eles.

Neste trabalho, investigamos, num experimento on-line, como universitários brasileiros lêem as anáforas conceituais. No experimento realizado, compararmos o tempo de leitura de anáforas pronominais simples e o de anáforas conceituais. A hipótese inicial era de que para compreendê-las, os leitores realizam representações de itens textuais associando-as a seus conhecimentos, e isso teria um custo processual, o que levaria a um maior tempo de leitura. Para descrever esse processo, usamos a teoria dos Frames Semânticos. A seguir, apresentaremos a anáfora conceitual, depois o experimento realizado para testar sua leitura e o seu processamento, assim como os resultados, a discussão e as considerações finais.

\section{A ANÁFORA CONCEITUAL}

Gernsbacher (1991, p. 83) denomina anáfora conceitual o pronome plural que não tem um antecedente correferencial; e Garnham et al. (1992, p. 257) delimitam como AC a anáfora pronominal que não tem um antecedente lingǘstico explícito, exigindo que o leitor se baseie no próprio contexto textual, a partir de um item lexical antecedente, para inferir o seu referente. Silva (2004, p. 42) aponta as propriedades da AC:

a) É representada por um pronome (Pro) plural;

b) O pronome baseia-se em um item lexical antecedente (SN) singular que permite ao leitor relacionar certos conceitos necessários para a compreensão;

c) O pronome não apresenta um antecedente correferencial;

d) A relação semântica entre a anáfora e o antecedente pode ser mais ou menos explícita. 
Em português, constatamos que as anáforas conceituais geralmente apresentam três formas de comportamento. Primeiramente elas:

1. Referem-se a uma generalização do antecedente, mas de maneira indeterminada, ou seja, não se referem a um objeto específico.

(3) Dê-me um prato. Eles estão no armário.

Em (3), a AC eles se refere aos pratos de maneira geral, não a um determinado prato, mas a todos os pratos que se encontram no armário. Alguém necessita de um dos pratos que estão no armário, portanto, há uma relação entre um elemento (um prato) e seu conjunto (pratos).

Em segundo lugar, as anáforas conceituais em português:

2. Apresentam uma relação de parte/todo, ou vice-versa, com o antecedente.

Nesse último caso, o termo "parte" indica relações de diversos tipos:

a) Coletivo/membro

(4) O governo canadense colheu a primeira safra oficial de maconha - destinada a usos medicinais. Mas, ao contrário das plantações ilegais do país, as ervas do governo são tão ruins que não puderam ser utilizadas. Para piorar, eles não têm ajuda - os especialistas nesse cultivo são considerados criminosos no país (Super Interessante. Ciência Maluca, edição 177, p. 20, jun. 2002).

Em (4), a $\mathrm{AC}$ eles não se refere $\mathrm{a} O$ governo canadense, mas às pessoas que participam do governo canadense e responsáveis pelo plantio oficial da maconha. $O$ escritor usa a $A C$ para se referir às pessoas que trabalham para a autoridade administrativa canadense, ou algo do tipo, e não à própria autoridade.

b) Classe/membro

(5) Até algum tempo, quando um ator queria se despir de seu personagem, ele tirava férias. Agora eles simplesmente mudam o penteado (ISTOÈ. Gente, no 1750 p. 64, abr. 2003). 
Em (5), o artigo indefinido no SN um ator já generaliza e não especifica um elemento de grupo; refere-se a uma classe, e a AC confirma essa generalização.

c) Localidade/membros

(6) Portugal chegou em uma nova terra que se chamou a (sic) vários anos de Brasil. Nessa nova terra, eles encontraram habitantes que os chamaram de índios, por ter pensado chegar às Índias. (redação de $5^{\mathrm{a}}$ série do Ensino Fundamental - Oliveira, 2001).

Nesse caso (6), a AC eles não se refere a Portugal, mas aos portugueses. Se a substituirmos pelo pronome ele, a construção parecerá estranha para o leitor, apesar de ser sintaticamente correta. Isso porque o leitor cria uma representação mental pela qual espera que os portugueses (aqueles que chegaram ao Brasil) sejam o referente e o responsável pela coerência do texto, e não o próprio país Portugal.

d) Conjunto/membro

(7) Você vai precisar de um copo. Eles estão no armário.

Em (7), a anáfora não se refere a um copo específico que se encontra no armário, mas ao conjunto dos copos que se tem no armário.

Por último, verificamos, quanto às anáforas conceituais em português, que:

3. Em alguns casos, não é possível a substituição de uma AC por uma AP (anáfora pronominal correferencial), pois ela perde o caráter indeterminado e generalizador, não representando uma relação de parte-todo. Acreditamos que muitas vezes a $\mathrm{AC}$ não pode ser substituída por AP por sofrer a influência de fatores pragmáticos e extratextuais, relacionados aos conhecimentos dos produtores e leitores. Observe os itens em negrito no exemplo:

(8) A tese criacionista afirma que a evolução da vida é lógica e perfeita demais para ter sido obra do acaso. Para eles, que usam a biologia molecular para contestar Darwin, a idéia de que descendemos de primatas é absurda (Morais, Super interessante, edição177, 06.02, p. 95). 
Em (8) AC eles tem como antecedente A tese criacionista, porém a anáfora não o retoma diretamente. A interpretação exige que se ativem possíveis sentidos para o referente, de tal forma que se deve lê-lo como criacionistas. Assim, eles não se refere mais a A tese criacionista, mas aos criacionistas, ou seja, os seguidores de tal teoria. O leitor deverá colaborar com o escritor do texto e considerar a não-concordância entre o antecedente e a anáfora como uma pista para encontrar o referente anafórico e estabelecer a coerência textual.

\section{A RELAÇÃO ENTRE ANÁFORA CONCEITUAL E A TEORIA DOS FRAMES}

A AC não concorda em número com o antecedente textual, não obedece à restrição morfológica (GERNSBACHER, 1991; OAKHILL et al, 1992), e isso poderia representar uma dificuldade a mais no complexo processo de leitura e compreensão. Assim, ao detectar o pronome anafórico, o leitor poderia ter dificuldade em compreender o uso do pronome, pois ele não estaria retomando um antecedente, mas remetendo a um antecedente a partir do qual o leitor compreenderia conceitualmente a anáfora. Para explicar esse processo, optamos pela Teoria dos Frames, pois ela permite o tratamento dinâmico da leitura com base em aspectos lingüísticos e extralingüísticos. Partimos da hipótese de que para compreender as anáforas, os leitores realizam representações de itens textuais, associando-as a seus conhecimentos.

Acreditamos que, durante a leitura, para compreender os itens lexicais de um texto, o leitor ativa frames que não ocorrem independentemente, mas associados. Um frame pode ser considerado uma maneira de formalizarmos as nossas representações mentais e organizarmos nossos conhecimentos. Ele é formado por $\operatorname{conceitos}^{7} \mathrm{e}$ relações entre esses conceitos que são codificados em itens lexicais e construções gramaticais. Consideramos que o escritor usa a AC como uma ferramenta para criar um significado e guiar o leitor pelo texto; já o leitor deve usá-la como um recurso para compreender o texto. As

\footnotetext{
${ }^{7}$ Conceito é representação a partir de uma palavra que combina conhecimento semântico e de mundo.
} 
palavras e construções gramaticais de um texto evocam uma compreensão, ou um frame, explicitado pelo escritor, a partir de associações de conceitos, e o leitor evoca um frame a partir desse texto a fim de compreendê-lo.

A Teoria dos Frames proporciona uma representação do conhecimento humano que é desenvolvido a partir de nossas experiências de vida. Como salienta Barsalou (1992, p. 27), as pessoas não armazenam componentes representacionais sem relacioná-los uns aos outros, e têm um extensivo conhecimento sobre as relações entre eles. A Teoria dos Frames proporciona uma representação do conhecimento humano que abrange uma grande variedade de representações conceituais. Segundo Barsalou (1992), os frames não podem ser considerados como rígidas configurações de atributos independentes, mas como estruturas relacionais dinâmicas cuja forma é flexível e dependente contextualmente. Para ele, um frame é formado, fundamentalmente, por três componentes:

a) Um conjunto de atributos e valores. Atributo é um conceito que descreve um aspecto de, pelo menos, alguns membros de uma categoria, e valor é um conceito subordinado ao de um atributo, mas numa determinada situação, de acordo com a necessidade do leitor.

b) Uma estrutura fixa. ${ }^{8}$ Os atributos, num frame, não ocorrem independentemente, mas conceitualmente relacionados. O que ele chama de estrutura fixa diz respeito a uma variedade de relações conceituais, como as espaciais, temporais, causais e intencionais.

c) Restrições. Os frames podem sofrer restrições quanto aos atributos, valores e contexto.

A compreensão da AC depende, portanto, do leitor, que tem como tarefa ativar seus conhecimentos lingüísticos e extralingüísticos, selecionar os atributos necessários para os conceitos ativados pelo texto e integrá-los, de modo a estabelecer a coerência textual.

Barsalou (1992, p. 29) considera que os frames podem representar todos os tipos de categorias (animadas, objetos, localizações, eventos físicos, mentais e assim por diante). Além disso, podem representar exemplares, eventos, seqüências de eventos, protótipos, membros de um

${ }^{8}$ Denominada structural invariants por Barsalou (1992). 
grupo, taxonomias e subordinações. Diante da complexidade de estruturas e relações que podem ser representadas a partir de frames, consideramos que esses podem representar as complexas relações entre a $\mathrm{AC}$ e seu antecedente, assim como um texto.

Esta pesquisa pode contribuir para que possamos entender mais como se dá a compreensão textual e as relações entre aspectos lingüísticos e extralingüísticos nesse processo. Pretendemos demonstrar que certos fenômenos, como a AC, só serão compreendidos se considerarmos esses dois aspectos. No caso dessa anáfora, o leitor não a compreenderá com base apenas na relação entre os itens lexicais. Para compreendê-la, ele deverá partir dessa relação e construir uma representação conceitual para esses itens.

Elaboramos um experimento a fim de se investigar a hipótese de que o tempo de leitura da $\mathrm{AC}$ seria maior do que $\mathrm{o}$ da anáfora pronominal correferencial (AP).

\section{MÉTODO}

Para confirmar se a leitura da AC exigiria cálculos inferenciais mais sofisticados do que a da AP, foi elaborado um experimento de leitura on-line. Esperamos constatar que o tempo de leitura da AC é maior que o da AP, pois na leitura daquela, o leitor se basearia num antecedente lingǘstico, a partir do qual ativaria conceitos a ele relacionados e selecionaria aquele que melhor se associasse à anáfora, ou seja, deveria realizar maiores cálculos inferenciais. Já na leitura da AP, o leitor estabeleceria a relação entre antecedente e anáfora mais rapidamente, pois essa relação se daria explicitamente e não violaria as restrições morfológicas.

Participaram do estudo 27 voluntários, alunos dos primeiros períodos dos cursos de Biologia, Educação Física, Enfermagem e Turismo de uma Universidade Comunitária, no Rio Grande do Sul. Esses voluntários tinham idades entre 19 e 26 anos; foram escolhidos de acordo com a disponibilidade para a atividade e por não estarem matriculados em cursos que trabalham diretamente com a interpretação de textos, como o de Letras, pois isso poderia direcionar a leitura deles. 
Criaram-se 40 seqüências textuais curtas, ou seja, cada uma composta por duas sentenças (anexo A). Dessas, 20 apresentavam um pronome iniciando a segunda sentença, sendo uma metade com AC e a outra com AP. Já as outras 20, apresentavam a segunda sentença iniciada simplesmente por um sintagma nominal. A partir dessas seqüências textuais, elaboraram-se 12 diferentes listas para serem lidas, cada uma com 36 seqüências, sendo que 16 delas representavam o foco de interesse da pesquisa, ou seja, $8 \mathrm{com}$ AC e $8 \mathrm{com}$ AP. As outras seqüências textuais foram elaboradas apenas para distraírem os participantes, ou seja, para evitar que eles percebessem que o foco da pesquisa era a anáfora pronominal.

Dessas seqüências textuais controladas no experimento, 8 iniciavam a segunda sentença com uma AC (2) e as outras com uma AP (1). Exemplos:

(1) O jornalista acompanhou os times ao estádio. Eles fizeram uma partida importante.

(2) O jornalista acompanhou o time ao estádio. Eles fizeram uma partida importante.

Após cada seqüência, aparecia uma pergunta, à qual o leitor deveria responder apenas sim ou não. Assim, após (2) e (1), aparecia: (9) O jornalista foi ao estádio?

Além das seqüências textuais com AC e AP, outras foram utilizadas, sem anáforas pronominais, cuja finalidade era não permitir que os sujeitos identificassem o objeto de estudo. Assim, foram usadas seqüências com pronomes, entre outros, como em 10.

(10) Maurício desligou a televisão agora. O programa acabara há pouco.

E, também, após essas seqüências textuais sem pronome, apresentou-se uma pergunta, à qual o sujeito deveria responder sim ou não. Após a leitura de 10, aparecia: Maurício desligon a televisão?

Os sujeitos foram testados individualmente, na presença do pesquisador, em uma pequena sala com uma mesa, duas cadeiras e um computador. Cada sujeito teve como tarefa ler, silenciosamente, cada seqüência textual de uma única lista, apresentada na tela do computador. Para a apresentação das listas, usamos o software DMDX, desenvolvido 
pelos professores K. I. Forster e J. C. Forster, da Universidade do Arizona, para experimentos psicológicos com estímulos visuais e auditivos. Esse software nos permitiu medir o tempo de leitura das anáforas, assim como o dos outros itens lexicais de cada seqüência.

A partir do tempo de leitura da AC e da AP, para cada seqüência e para cada sujeito, fornecidos pelo DMDX, cálculos estatísticos foram feitos para verificarmos se esta (AP) seria lida mais rapidamente do que aquela (AC). De posse do tempo de leitura de cada item de cada seqüência e de cada sujeito do experimento, verificamos o tempo médio de leitura da AC e o da AP, o dos verbos que as seguiam e o dos complementos (considerando objetos e adjuntos). A partir daí, realizamos a análise de variância (ANOVA) para os efeitos principais.

\section{RESULTADOS}

De posse dos tempos médios de leitura das seqüências textuais com anáforas conceituais e pronominais fornecidos pelo DMDX, inicialmente, obtivemos os tempos de leitura do pronome anafórico, do verbo e do complemento ${ }^{9}$ em cada seqüência apresentada a cada sujeito. Esse resultado é apresentado no Gráfico 1.

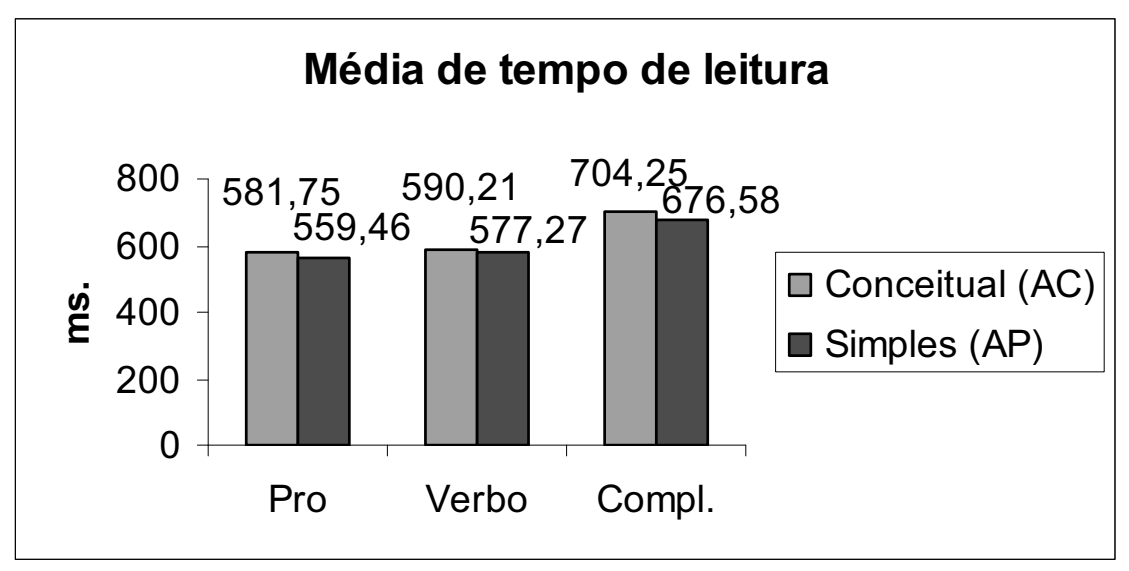

Gráfico 1 - Média de tempo de leitura (em ms.) para os 27 sujeitos.

Os resultados da análise de variância mostram que a diferença entre os tempos de leitura da $\mathrm{AC}$ e da $\mathrm{AP}$ não é significativa em

\footnotetext{
${ }^{9}$ Nessa posição ocorrem tanto objetos quanto adjuntos.
} 
$\mathrm{F}_{1}{ }^{10}(1,1119)=1,2171, \quad \mathrm{p}>0,28, \quad$ mas é significativa em $\mathrm{F}_{2}{ }^{11}(1,1134)=23,7423, \mathrm{p}<0,05$. Uma análise post hoc (experimento de Fisher) não mostra significância para as diferenças de relação anafórica (anáfora conceitual $\mathrm{X}$ anáfora pronominal) de acordo com a posição (pronome, verbo ou complemento), mas indica uma alta significância $(\mathrm{p}<0,0001)$ para a diferença entre a posição do complemento em relação às anteriores.

Sendo assim, resolvemos verificar a média de tempo de leitura para cada sujeito. Ao examinarmos o comportamento dos sujeitos, individualmente, percebemos que alguns não confirmaram a hipótese de que a AC seria lida mais lentamente do que a AP. Os resultados da análise de variância mostraram que a diferença entre os tempos de leitura da AC e da AP não foi significativa.

Depois disso, analisamos mais atentamente as médias de leitura das anáforas, ou seja, separamos a análise em dois grupos de sujeitos. Assim, obtivemos o grupo A, aquele dos sujeitos que leram as anáforas conceituais mais lentamente, e o grupo B, o dos que leram as anáforas pronominais mais lentamente. Assim, o grupo A foi formado por sujeitos que confirmaram a hipótese e o grupo B formado por sujeitos que refutaram a hipótese.

Para o grupo A, a ANOVA de efeitos principais mostrou que a diferença entre o tempo de leitura da $\mathrm{AC}$ e o da AP é significativa $\left[\mathrm{F}_{1}(1,662)=4,9658, \mathrm{p}<0,05\right.$ e $\left.\mathrm{F}_{2}(1,672)=10,9952, \mathrm{p}<0,09\right]$. Também uma análise post hoc (experimento de Fisher) mostrou que a diferença de tempo de leitura do pronome nas duas condições (AC e AP) é significativa $(p<0,03)$. Já os tempos de leitura do verbo e do complemento não foram estatisticamente diferentes, mas mostraram uma tendência de também serem maiores nos casos da AC.

Para o grupo B, realizada a ANOVA de efeitos principais, verificou-se que a diferença entre o tempo de leitura da AC e o da AP não foi significativa $\left[\mathrm{F}_{1}(1,457)=0,3783, \mathrm{p}>0,55\right.$ e $\mathrm{F}_{2}(1,457)=0,5699$, $\mathrm{p}>0,52]$.

\footnotetext{
${ }^{10}$ Lembramos que $\mathrm{F}_{1}$ é o resultado de uma ANOVA em que a variável sujeitos é tomada como fator aleatório na análise.

${ }^{11} \mathrm{~F}_{2}$ é o resultado de uma ANOVA em que a variável textos é tomada como fator aleatório na análise.
} 
Assim, resolvemos comparar os dois grupos. A análise post hoc (novamente com experimento de Fisher) indicou que apenas a diferença entre os tempos de leitura do pronome, na comparação entre os sujeitos do grupo A e os do grupo B (os sujeitos que levaram mais tempo para ler o pronome na condição de $\mathrm{AC}$ do que na condição de $\mathrm{AP}$ ), foi significativa ( $p>0,0002)$. Vale, entretanto, notar que a diferença na leitura do verbo, no caso das anáforas conceituais, apresentou diferença marginalmente significativa $(\mathrm{p}>0,05)$. As médias de leitura entre os sujeitos do grupo A e do grupo B para as anáforas conceituais e as pronominais estão representadas respectivamente nos Gráficos 2 e 3.

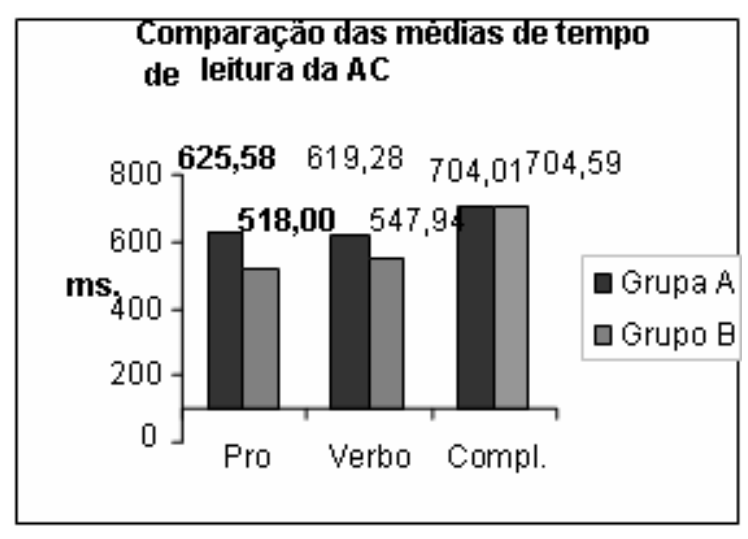

Gráfico 2 - Médias de tempo de leitura da AC.

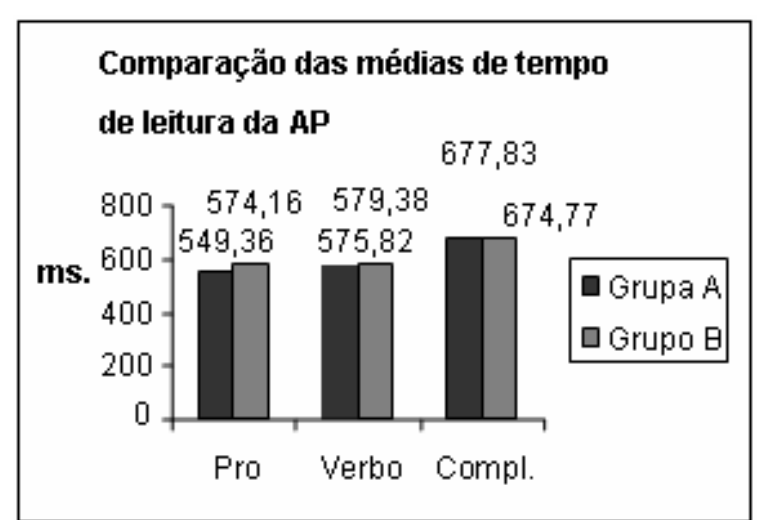

Gráfico 3 - Médias de tempo de leitura da AP.

\section{DISCUSSÃO}

A hipótese sobre processamento, apesar de teoricamente sustentável, de maneira geral, não se confirmou, pois a diferença de tempo de leitura entre a anáfora conceitual e a pronominal não foi significativa. Porém, de forma específica, houve dois comportamentos diferentes entre os sujeitos: alguns confirmaram a hipótese, lendo as anáforas conceituais mais lentamente, e outros a inverteram, lendo as anáforas pronominais mais lentamente. Nesse caso, a diferença entre o tempo de leitura da AC e o da AP foi significativa somente para os sujeitos que leram a $\mathrm{AC}$ mais lentamente, mas não para aqueles que leram a AP mais lentamente. 
Os que leram a AC mais lentamente pareceram seguir a estratégia de se apoiar na concordância para a ativação de frames e a seleção de seus atributos. Quando perceberam não-concordância, buscaram, em sua memória, informações conceituais a partir de itens lexicais, ativando novos frames com atributos e valores e procuraram, nessa estrutura, o conceito ao qual a anáfora se refere, compreendendo a relação conceitual entre a AC e seu antecedente. Nesse processo, fica claro um maior custo em termos cognitivos, resultando em um maior tempo de leitura da AC em oposição à AP.

Já para os que leram a AP mais lentamente, podemos levantar duas hipóteses. A primeira é que não foram influenciados pelo fato de haver, ou não, concordância entre a anáfora e o antecedente. Na leitura da AC ou da AP, esses sujeitos não se guiaram pelos aspectos morfológicos da anáfora e operaram diretamente com as informações conceituais que são organizadas em frames. Assim, também podemos levantar a hipótese de que esses sujeitos não tenham percebido essa incongruência, ou talvez tenham se guiado, durante a leitura, mais em aspectos extralingüísticos no que nos lingüísticos, como, por exemplo, na não-concordância. Se eles não perceberam a relação estabelecida entre antecedente e anáfora, podem ter lido os dois casos como idênticos, mas isso só poderia ser comprovado se houvesse, no experimento, a possibilidade de verificar acertos e erros na recuperação da anáfora. É isso que pretendemos fazer no próximo trabalho.

A partir da indicação desses dois grupos de resultados, consideramos que os sujeitos desses dois grupos usaram estratégias diferentes. Isso não é uma surpresa, pois a leitura é um processo dinâmico, dependente de fatores, tanto lingǘsticos quanto extralingüísticos, podendo variar de sujeito para sujeito, dependendo dos seus conhecimentos. As pesquisas sobre compreensão de sentenças e textos demonstram que vários fatores afetam esse processo. Alguns fatores lingüísticos como a concordância ou não-concordância entre os marcadores morfológicos das anáforas e de seus antecedentes (TYLER; MARSLEN-WILSON, 1982; GERNSBACHER, 1991; OAKHILL et al., 1992), a capacidade do leitor de combinar a informação dada no texto com conhecimentos que ele ativa da memória (WAGENER-WENDER; WENDER, 1990; BARSALOU, 1992; FILLMORE; BAKER, 2001; BOELLA, 2002), e fatores extralingüísticos como os objetivos de leitura, 
as expectativas geradas a partir do texto e o conhecimento prévio e de mundo (KLEIMAN, 1989; KOCH; TRAVAGLIA, 1989, 1999; WAGENER-WENDER; WENDER, 1990; KOCH, 1999; SILVA, 2004) podem interferir na leitura e compreensão de textos.

Assim, não devemos nos esquecer de que esses fatores podem ter influenciado a leitura dos sujeitos na situação experimental. Devido às influências que estão em jogo nessa situação, muitos criticam o uso de experimentos nos estudos lingüísticos. É claro que os experimentos não nos dão provas definitivas sobre os fenômenos abordados, pois não podemos observá-los empiricamente, mas nos oferecem evidências e perspectivas para novas abordagens. Derwing e Almeida (2005) oferecem uma discussão interessante sobre o uso de métodos experimentais na lingüística.

Também é importante ressaltar que leitores são indivíduos únicos, produzem representações com diferentes níveis de especificidade, guiados por vários parâmetros, como capacidade de memória de trabalho, domínio de conhecimento e objetivos de leitura (KLEIMAN, 1989; WAGENER-WENDER; WENDER, 1990). Por isso a tríade leitor/texto/escritor é constantemente retomada por pesquisadores.

$\mathrm{Na}$ resolução da AC, consideramos que, para alguns sujeitos, a não-concordância será importante para ativar certos conceitos organizados em frames e, para outros, não. Ou seja, eles usam estratégias diferentes, de forma que ora o processo é influenciado por um fator lingüístico, como a não-concordância de número entre a anáfora $\mathrm{e} o$ antecedente, ora é influenciado por outros fatores, como os conhecimentos de mundo e o modo como eles organizam tal conhecimento. Assim, nem sempre o processo da leitura e compreensão de anáforas dependerá de um fator lingüístico para ser resolvido, pois o leitor poderá resolvê-las guiando-se por outros fatores, como o seu conhecimento de mundo e a maneira como ele organiza tal conhecimento.

\section{CONSIDERAÇÕES FINAIS}

Os resultados desse experimento indicaram que, na leitura das anáforas, os sujeitos usaram dois tipos de estratégias diferentes. Isso 
reafirma o importante papel do leitor na atividade de leitura, ao mesmo tempo em que nos faz repensar a leitura como um processo. Um modelo de leitura deve considerar o fato de que os leitores não se comportam da mesma forma ao lerem. Isso ficou claro no trabalho, pois constatamos que, para alguns leitores, a não concordância de número entre anáfora e antecedente influenciou e dificultou a leitura, o que não aconteceu em relação a outros, para os quais essa não-concordância não teve importância. Tudo depende, portanto, do trabalho do leitor durante a construção e integração de informações. É interessante ressaltar que, no caso da AC, houve uma diferença marginalmente significativa no tempo de leitura do verbo. Isso faz pensar que o sujeito pode estar tentando integrar as informações anteriores para compreendê-las.

Como não se pode explicar a AC com uma análise puramente lingüística, usamos a Teoria dos Frames apresentada por Barsalou (1992). Um frame pode ser considerado como uma ferramenta que ajuda a explicar as relações conceptuais entre itens lingüísticos, contextuais e cognitivos, co-ocorrentes na atividade da leitura.

Com este trabalho, esperamos incentivar outros, principalmente na análise de textos, uma vez que a teoria não se encontra estagnada no tempo, pois, como ficou demonstrado, dá conta da dinâmica da leitura, considerando aspectos que envolvem tanto pressupostos lingǘsticos e cognitivos quanto conhecimentos do leitor. Dessa forma, torna-se uma ferramenta que pode explicar, com mais precisão, o aspecto interativo da leitura e da compreensão.

Em suma, os resultados sugerem que os alunos compreendem a AC, mas com processamento diferente, e novos experimentos devem ser realizados para se analisar mais detalhadamente o processamento dessa anáfora.

\section{REFERÊNCIAS}

APOTHÉLOZ, D. Papel e funcionamento da anáfora na dinâmica textual. In: CAVALCANTE, M. M.; RODRIGUES, B. B.; CIULLA, A. (Orgs.).

Referenciação. São Paulo: Contexto, 2003. p. 53-84.

ARNOLD, J. E. Reference form and discourse patterns. Dissertation

(Doctor of Philosophy) - Stanford University, Department of Linguistics, 1998. 
BARSALOU, L. W. Frames, concepts, and conceptual fields. In: LEHRER, A., KITTAY, E. F. Frames, fields, and contrasts: new essays in semantic and lexical organization. New Jersey: Lawrence Erlbaum Associates, 1992. p. 21-74.

BOELLA, G.; LESMO, L. Mental models theory and anaphora. In:

Proceedings of Cognitive Science Conference, 2002. Available on: <www.di.unito.it/ guido/PS/boella-cogsci02.pdf.> Cited: 20 Jun. 2003.

CAVALCANTE, M.M.; BIASI-RODRIGUES, B.; CIULLA, A. (Orgs.). Referenciação. São Paulo: Contexto, 2003.

CHAMPOLLION, L. On the (ir)relevance of psycholinguistics for anaphora resolution. In: POESIO, M.; ARTSTEIN, R. Ambiguity in anaphora workshop: proceedings. Málaga: [S.N.], 2006. p. 13-21. Available on: http://www.ling.upenn.edu/ champoll/irrelevance-psycholinguistics.pdf.> Acessed in: Mar. 20, 2007.

CLARK, H. Brinding. In: WASON, P.; JOHNSON-LAIRD, P. (Eds.). Thinking: readings in cognitive sciences. Cambridge: Cambridge University Press, 1977. p. 417-420.

DERWING, B. L.; ALMEIDA, R. G. Métodos experimentais em lingüística. In: MAIA, M.; FINGER, I. (Eds.). Processamento da linguagem. Pelotas: Educat, 2005. Diponível em: <http://alcor.concordia.ca/ almeida/DerwingdeAlmeida-BP-7d.pdf>. Acesso em: jun. 2008.

FILLMORE, C. J. The case for case. In: BACH, E.; HARMS, R.T. (Eds.). Universals in linguistic theory. New York: Holt, Rinehart \& Winston, 1986. p. 1-88.

FILLMORE, C. J.; BAKER, C. F. Frame semantics for text understanding. In: Proceedings of WorldNet and other lexical resources workshop.

Pittsburgh. NAACL, 2001. Available on:

$<$ http://framenet.icsi.berkeley.edu/ framenet/papers/Fncrime.pdf $>$ Cited: 12 Jul. 2003.

GARNHAM, A.; OAKHILL, J.; CRUTTENDEN, H. The role of implicit causuality and gender cue in the interpretation of pronouns. Language and cognitive processes, v. 7, p. 231-256, 1992.

GERNSBACHER, M. A. Comprehending conceptual anaphors. Language and cognitive processes, v. 6, n. 2, p. 81-105, 1991.

HAAG, C. R.; OTHERO, G. A. O processamento anafórico: um experimento sobre a resolução de ambigüidades em anáforas pronominais. Linguagem em (Dis)curso, v.4, n.1, jul./dez. 2003. Disponível em: <http:// 
www3.unisul.br/paginas/ensino/pos/linguagem/0401/03.htm>. Acesso em: 21 fev. 2006.

ISTOÉ, n. 1749, p. 109, 16 abr. 2003.

ISTOÉ GENTE, n.1750, p. 64, 9 abr. 2003.

KLEIMAN, A. Texto e leitor: aspectos cognitivos da leitura. São Paulo: Pontes, 1989.

KOCH, I. G. V. Referenciação: construção discursiva. Ensaio apresentado em concurso para professor Titular em Análise do Discurso no IEL/UNICAMP, Dez, 1999.

Desvendando os segredos do texto. São Paulo: Cortez, 2002.

; MARCUSCHI, L. A. Processos de referenciação na produção

discursiva. D.E.L.T.A., v. 14, Número Especial, p. 169-190, 1998.

; TRAVAGLIA, L. C. Texto e coerência. São Paulo: Cortez, 1989.

; __ A referenciação textual como estratégia cognitivo-interacional.

In: BARROS, K. S. M. (Org.). Produção textual: interação, processamento, variação. Natal: EDUFURN, 1999. p. 69-80.

LEFFA, V. J. A resoluçăo da anáfora no processamento da língua natural.

Relatório final de Pesquisa. Set. 2000. Universidade Católica de Pelotas.

Disponível em: <http://www.leffa.pro.br/anafor_rel.htm>. Acesso em: $21 \mathrm{fev}$. 2006.

MARCUSCHI, L. A. Anáfora indireta: o barco textual e suas âncoras. In: ENCONTRO DO CELSUL, 7. Curitiba, 2000a. Anais... . Anáfora sem antecedente explícito. In: PRETI, D. (Org.). Fala e escrita em questão. São Paulo: Humanitas, 2000b. p. 191-240.

Quando a referência é uma inferência. Conferência pronunciada no GEL, UNESP, Assis, SP, mai. 2000c.

OAKHILL, J.; GARNHAM, A.; GERNSBACHER, M. A.; CAIN, K. How natural are conceptual anaphors? Language and cognitive processes, v.7, p. 257-280, 1992.

SILVA, A. A leitura e compreensão da anáfora conceitual. 2004. 163 f. Tese (Doutorado em Lingüística) - Instituto de Estudos Linguisticos, Universidade Estadual de Campinas, Campinas. 
SWINNEY, D. A.; OSTERHOUT. Inference generation during auditory language comprehension. In: GRAESSER, A. C.; BOWER, G. H. (Eds.).

Inferences and text comprehension. New York: Academic Press, 1990. p. 1734.

TYLER, L. K.; MARSLEN-WILSON, W. The resolution of discourse anaphors: some on-line studies. Text, v. 2, p. 263-291, 1982.

WAGENER-WENDER, M.; WENDER, K. F. Expectations, mental representations, and spatial inferences. In: GRAESSER, A. C.; BOWER, G. H. (Eds.). Inferences and text comprehension. New York: Academic Press, 1990. p. 137-158.

\section{Anexo A - As seqüências textuais controladas no experimento on-line:}

1 O jornalista acompanhou o time Eles fizeram uma partida ao estádio importante.

2 O jornalista acompanhou os Eles fizeram uma partida times ao estádio importante.

3 Jonas denunciou o banco por Eles cometeram erros graves fraude. nas faturas.

4 Jonas denunciou os bancos por Eles cometeram erros graves fraude. nas faturas.

5 Ana foi ao museu bem cedo Eles recebem pouca gente nesse horário

6 Ana foi aos museus bem cedo Eles recebem pouca gente nesse horário

7 Nós fomos ao hospital na Eles permanecem de plantão madrugada. toda noite.

8 Nós fomos aos hospitais na Eles permanecem de plantão madrugada. toda noite.

9 Cláudia foi à reunião do Eles propuseram greve geral da sindicato pela manhã. categoria.

10 Cláudia foi às reuniões do Eles propuseram greve geral da sindicato pela manhã.

11 Luiza esperou o bloco na Eles estavam alegres e avenida. animados.

12 Luiza esperou os blocos na Eles estavam alegres e 
avenida.

13 Pedro foi à apresentação do Eles cantam somente música coral católico.

animados. sacra.

14 Pedro foi às apresentações do Eles cantam somente música coral católico. sacra.

15 O governador convocou o Eles combaterão o tráfico no batalhão de elite.

16 O governador convocou os Eles combaterão o tráfico no batalhões de elite. estado.

17 A polícia multou o comboio na Eles estavam em alta estrada. velocidade.

18 A polícia multou os comboios na Eles estavam em alta estrada. velocidade.

19 O professor conversou com o Eles apresentam o trabalho na grupo do seminário. terça-feira.

20 O professor conversou com os Eles apresentam o trabalho na grupos do seminário. terça-feira.

21 Eu consultei o colégio do estado. Eles dispõem de recursos de informática.

22 Eu consultei os colégios do Eles dispõem de recursos de estado. informática.

23 Susana encontrou o casal no Eles estavam muito unidos e cinema. felizes.

24 Susana encontrou os casais no Eles estavam muito unidos e cinema. felizes.

25 Nós recorremos ao tribunal de Eles julgaram o caso a nosso alçada. favor.

26 Nós recorremos aos tribunais de Eles julgaram o caso a nosso alçada. favor.

27 O juiz visitou o presídio da Eles reclamaram da capital. superlotação das celas.

28 O juiz visitou os presídios da capital.

Eles reclamaram

da

29 Paulo sempre vota em partido de esquerda. superlotação das celas.

30 Paulo sempre vota em partidos Eles apresentam propostas de esquerda. progressistas. 
31 O diretor chamou o elenco ao Eles agradeceram os aplausos palco. do público.

32 O diretor chamou os elencos ao Eles agradeceram os aplausos palco. do público.

33 Mônica vai ao supermercado do Eles fazem ofertas muito boas. centro.

34 Mônica vai aos supermercados Eles fazem ofertas muito boas. do centro.

35 Ricardo foi ao cartório de Eles fizeram as escrituras dos imóveis. terrenos.

36 Ricardo foi aos cartórios de Eles fizeram as escrituras dos imóveis. terrenos.

37 O fiscal inspecionou o bar no Eles pagaram uma multa mês passado. pesada.

38 O fiscal inspecionou os bares no Eles pagaram uma multa mês passado. pesada.

39 Roberto foi ao escritório de Eles prepararam projetos muito arquitetura. bonitos.

40 Roberto foi aos escritórios de Eles prepararam projetos muito arquitetura. bonitos.

Recebido em 20/04/07. Aprovado em 26/06/08.

Title: Reading and conceptual anaphor processing

Author: Adriana da Silva

Abstract: This study presents an investigation of conceptual anaphor reading (CA). The work analyzed how a group of undergraduate students read anaphors. A self-paced test was carried out and some sentences containing conceptual anaphors and others with pronominal anaphors (PA) were presented. Our initial hypothesis, that conceptual anaphors were more slowly read than other anaphors, was not confirmed. Results demonstrated that there was no significant difference on the reading of anaphors. Therefore, we concluded that reading is a dynamic process and that readers have an important role in this process.

Keywords: cognition; reading; textual cohesion; conceptual anaphor; pronominal anaphor.

Titre: La lecture et le processus de l'anaphore conceptuelle

Auteur: Adriana da Silva 
Résumé: On présente une recherche sur la lecture de l'anaphore conceptuelle (AC). Dans un essai avec des étudiants universitaires, on a recherché comment eux, ils lisent les anaphores. On a fait un test self-paced et on a présenté des phrases contenant des anaphores conceptuelles et d'autres avec des anaphores pronominales (AP). On attendait que les anaphores conceptuelles fussent lues plus doucement que les autres. Les résultats ont démontré qu'il n'y a pas eu de différence marquante dans la lecture des anaphores. Notre conclusion porte sur la lecture qui est un procès dynamique et que les lecteurs ont un rôle important dans ce procès.

Mots-clés: cohésion textuelle ; anaphore conceptuelle; anaphore pronominale; lecture; cognition.

Título: La lectura y el procesamiento de la anáfora conceptual

Autor: Adriana da Silva

Resumen: Presentamos una investigación sobre la lectura de anáfora conceptual (AC). En un experimento con universitarios, investigamos como ellos leen las anáforas. Realizamos una prueba self-paced y presentamos frases conteniendo anáforas conceptuales y otras con anáforas pronominales (AP). Esperábamos que las anáforas conceptuales fuesen leídas más lentamente de lo que las otras anáforas. Los resultados mostraron que no hubo diferencia significativa en la lectura de las anáforas. Nuestra conclusión es que la lectura es un proceso dinámico y que los lectores tienen un papel importante en este proceso.

Palabras-clave: cohesión textual; anáfora conceptual; anáfora pronominal; lectura; cognición. 